\title{
Death and cadavers: knowledge, skills and attitudes will have to change
}

*Walsh K

Dear Editor,

Charlier et al are to be praised for bringing to light the beliefs of medical students from Parakou about death and cadavers ${ }^{1}$. Greater insight into such beliefs will be the first step to changing these beliefs. Yet insight into beliefs alone is insufficient. A programmatic approach will be needed to bring about changed practice.

First of all we will need a deeper insight into the knowledge of medical students about autopsies (and not just their beliefs). Secondly we will need an insight into students' skills at explaining autopsies to relatives. Excellent communication skills in this regard will be essential. Thirdly we will need an assessment of students' and doctors' motivation to change their practice. Without motivation, change will simply not happen. Fourthly even with insight into all these areas, there may be barriers to change that may prevent doctors from changing their practice even should they wish to. For example if doctors wish to change their practice with regard to requesting autopsies but the general public and thus relatives do not want their deceased relative to have an autopsy, then changed practice will not occur.

Once the many possible barriers to change have been identified, then measures to overcome these barriers will have to be put in place. Once again a programmatic approach will be required. Educational materials will likely help students improve their knowledge and beliefs. Communication skills teaching should help students overcome any deficits in this area. Recruiting respected opinion leaders to deliver education should help - especially in overcoming long and deeply held beliefs. Lastly patient and public education should be aligned with that of student and healthcare professional education. Once public opinion begins

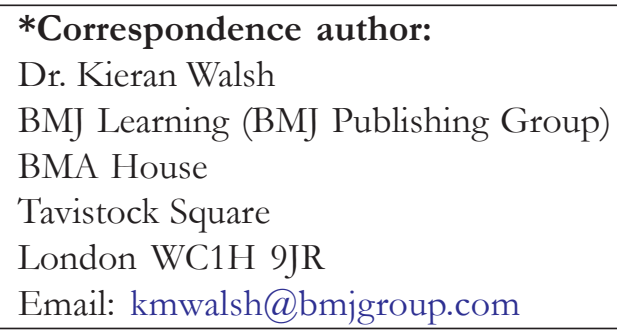

to change then better educated doctors will be reaching out to a more receptive audience.

Yours sincerely,

Dr Kieran Walsh

African Health Sciences 2013; 13(2): 525 http:// dx.doi.org/10.4314/ahs.v13i2.47

\section{References}

1. Charlier P, Brun L, de la Grandmaison G, Hervé C. Medical students from Parakou (Benin) and West-African traditional beliefs on death and cadavers. Afr Health Sci. 2012; 12(4):443-5. 